\title{
Roles of Serotonergic and Adrenergic Receptors in the Antinociception of Selective Cyclooxygenase-2 Inhibitor in the Rat Spinal Cord
}

\author{
Department of Anesthesiology and Pain Medicine, Chonnam National University Hospital, Gwangju, Korea \\ Hye Jin Jeong, MD, Seong Heon Lee, MD, Soo Young Cho, MD, Cha Sup Lee, MD, \\ Cheol Won Jeong, MD, Myung Ha Yoon, MD, and Woong Mo Kim, MD
}

\section{Background:}

The analgesic mechanisms of cyclooxygenase (COX)-2 inhibitors have been explained mainly on the basis of the inhibition of prostaglandin biosynthesis. However, several lines of evidence suggest that their analgesic effects are mediated through serotonergic or adrenergic transmissions. We investigated the roles of these neurotransmitters in the antinociception of a selective COX-2 inhibitor at the spinal level.

\section{Methods:}

DUP-697, a selective COX-2 inhibitor, was delivered through an intrathecal catheter to male Sprague-Dawley rats to examine its effect on the flinching responses evoked by formalin injection into the hindpaw. Subsequently, the effects of intrathecal pretreatment with dihydroergocristine, prazosin, and yohimbine, which are serotonergic, $\alpha 1$ adrenergic and $\alpha 2$ adrenergic receptor antagonists, respectively, on the analgesia induced by DUP-697 were assessed.

\section{Results:}

Intrathecal DUP-697 reduced the flinching response evoked by formalin injection during phase 1 and 2. But, intrathecal dihydroergocristine, prazosin, and yohimbine had little effect on the antinociception of intrathecal DUP-697 during both phases of the formalin test.

\section{Conclusions:}

Intrathecal DUP-697, a selective COX-2 inhibitor, effectively relieved inflammatory pain in rats. Either the serotonergic or adrenergic transmissions might not be involved in the analgesic activity of COX-2 inhibitors at the spinal level. (Korean J Pain 2011; 24: 179-184)

\section{Key Words:}

analgesia, COX-2 inhibitor, inflammatory pain, mechanism, spinal cord. 


\section{INTRODUCTION}

Cyclooxygenase (COX)-2 inhibitors are one of the most commonly used types of analgesics. Inhibition of COX-2, which is increased in the spinal cord after peripheral inflammation [1], and the consequent blockade of prostaglandin biosynthesis, have been widely accepted as the mechanisms underlying the analgesic action of this group of drugs. However, several lines of evidence suggest that their analgesic effects are also exerted by a variety of peripheral and central mechanisms including endocannabinoids, nitric oxide, and the monoaminergic, cholinergic, and opioid systems [2,3].

Among them, monoamines such as serotonin (5-hydroxytryptamine, 5-HT) and norepinephrine (NE), and their corresponding receptors, were shown to be present within the spinal cord $[4,5]$ and to play an important role in the modulation of nociceptive transmission [6]. The involvement of 5-HT and NE in the antinociceptive effects of COX-2 inhibitors has already been documented in other reports with animal models. Orally administered rofecoxib increased 5-HT levels in the rat frontal cortex, and the analgesic activity of this COX-2 inhibitor was significantly decreased by depletion of central 5-HT [7]. Additionally, destruction of bulbospinal noradrenergic projection neurons by intracerebroventricular injection of 6-hydroxydopamine was shown to eliminate the effect of nonsteroidal anti-inflammatory drugs [8]. Taken together, these data indicate that there is an interaction of COX-2 inhibitors with the central serotonergic and adrenergic systems. However, at the spinal level, these interactions are not clearly defined.

The aim of this study was to clarify the roles of $5-\mathrm{HT}$ and $\mathrm{NE}$ on the analgesic activity of $\mathrm{COX}-2$ inhibitors at the spinal level. Therefore, 5-HT receptor antagonists and $\alpha 1$ adrenergic and $\alpha 2$ adrenergic receptor antagonists were intrathecally administered to investigate their ability to reverse the antinociception produced by $\mathrm{COX}-2$ inhibitors in a rat model of inflammatory pain.

\section{MATERIALS AND METHODS}

All procedures were carried out with the approval of the Institutional Animal Care Committee, Research Institute of Medical Science. Male Sprague-Dawley rats weighing 250-300 $\mathrm{g}$ were used in these experiments. The rats were housed in a vivarium maintained at $20-23^{\circ} \mathrm{C}$ with a $12 \mathrm{~h}$ light/dark cycle, and were given food and water ad libitum. A polyethylene tube (PE-10) was catheterized and inserted into the subarachnoid space in sevofluraneanesthetized rats as described previously $[9,10]$. The rats were closely monitored and, if motor abnormalities appeared, they were euthanized through a volatile anesthetic overdose. Normal rats were kept in individual cages, and a period of not less than 5 days was allowed for each rat to recover from intrathecal catheterization. Rats displaying apparently normal behavior and weight gain were then assigned to the experiment.

The following drugs were used in this study: DUP-697

Table 1. Pharmacological Characteristics of the Experimental Drugs

\begin{tabular}{|c|c|c|c|c|c|}
\hline Drug \& chemical name & \multicolumn{3}{|c|}{$\begin{array}{l}\text { Subtype affinity } \\
\qquad(\mathrm{pA} 2)^{\star}\end{array}$} & $\begin{array}{l}\text { Elimination } \\
\text { half-life (hour) }\end{array}$ & $\begin{array}{l}\text { Dose } \\
(\mu g)\end{array}$ \\
\hline \multicolumn{6}{|l|}{ Dihydroergocristine: } \\
\hline \multirow{2}{*}{$\begin{array}{l}\text { (5' } \alpha, 10 \alpha)-9,10 \text {-Dihydro-12'-hydroxy-2'-(1-methylethyl)- } \\
5^{\prime} \text {-(phenylmethyl)-ergotaman-3',6',18-trione mesylate }\end{array}$} & Non-selective & -HT receptor ar & gonist & 13.6 & 3 \\
\hline & $\begin{array}{c}\alpha 1 \\
\text { (vs noradrenalin) }\end{array}$ & $\begin{array}{c}\alpha 2 \\
\text { (vs clonidine) }\end{array}$ & $\alpha 2 / \alpha 1^{\dagger}$ & & \\
\hline Prazosin: & & & & & \\
\hline $\begin{array}{c}\text { 1-(4-Amino-6,7-dimethoxy-2-quinazolinyl)-4- } \\
\text { (2-furanylcarbonyl)piperazine hydrochloride } \\
\text { Yohimbine: }\end{array}$ & $8.18 \pm 0.11$ & $5.94 \pm 0.10$ & 0.006 & 1.9 & 3 \\
\hline 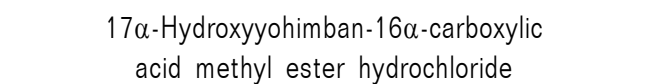 & $6.49 \pm 0.06$ & $8.14 \pm 0.05$ & 45 & 7.7 & 10 \\
\hline
\end{tabular}

Data are expressed as mean \pm SEM. ${ }^{\star}$ Log[concentration of antagonist which necessitates doubling the concentration of agonist] ${ }^{-1}$,

${ }^{\dagger}$ Calculated from the antilogarithm of the difference between the $\mathrm{pA}_{2}$ values obtained at $\alpha 2$ and $\alpha 1$ adrenergic receptors. 
(5-Bromo-2-(4-fluorophenyl)-3-[4-(methylsulfonyl)phenyl]-thiophene), dihydroergocristine mesylate (Research Biochemical Internationals, Natick, MA, USA), and prazosin hydrochloride and yohimbine hydrochloride (Sigma Aldrich Co., St. Louis, MO, USA). All drugs were dissolved in 100\% dimethylsulfoxide (DMSO) and intrathecally administered using a hand-driven, gear-operated syringe pump. The drugs were delivered in a volume of $10 \mu \mathrm{l}$ solution, followed by an additional $10 \mu \mathrm{l}$ of saline to flush the catheter.

On experiment days, the rats were placed in a restraining cylinder and held for 20 min for adaptation. To investigate the effect of COX-2 inhibitor in the formalin test, rats were treated intrathecally with vehicle or
DUP-697 (10, 30, 100, $300 \mu \mathrm{g})$, administered 10 min before the formalin test ( $\mathrm{n}=7$ in each group). Doses of DUP-697 were determined based on previous studies [2]. Next, rats were pretreated with dihydroergocristine $(5-\mathrm{HT}$ receptor antagonist, $3 \mu \mathrm{g}$ ), prazosin ( $\alpha 1$ adrenergic receptor antagonist, $3 \mu \mathrm{g}$ ), or yohimbine ( $\alpha 2$ adrenergic receptor antagonist, $10 \mu \mathrm{g})$, in order to determine the roles of these agents in the activity of DUP-697 ( $\mathrm{n}=7$ in each group). Pharmacological characteristics of these antagonists are presented in Table 1 [11-15]. Doses of the drugs were chosen based on previous experiments, in which the maximum dosage that did not affect the control formalin response or cause side effects such as motor impairment was de-

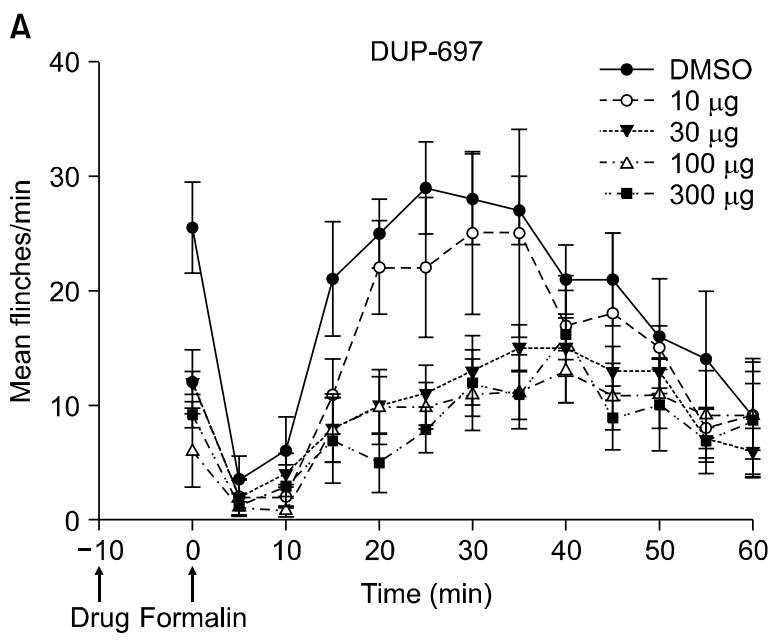

B

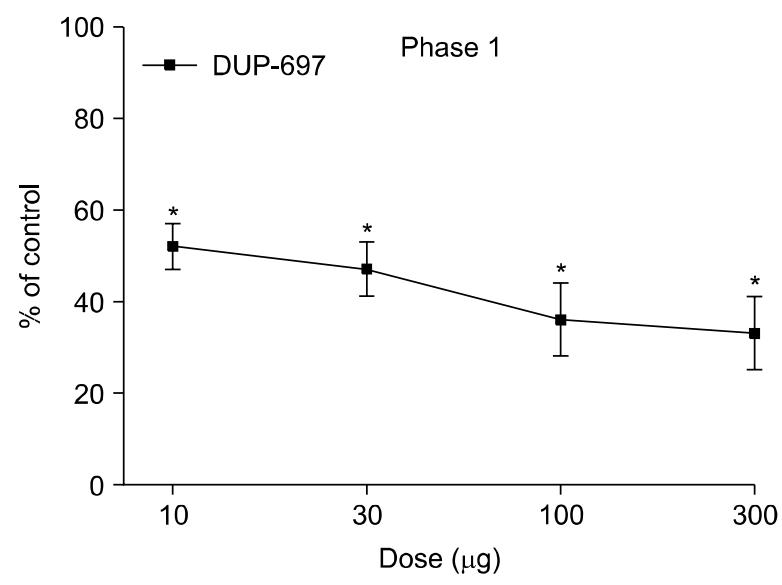

C

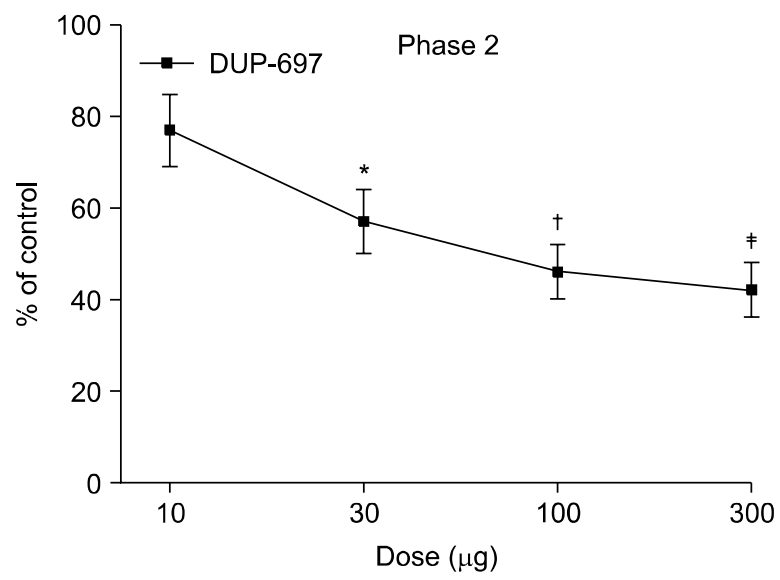

Fig. 1. Time course (A) and dose-response curves of intrathecal DUP-697 on flinching response during phase 1 (B) and phase 2 (C) in the formalin test. DUP-697 was administered $10 \mathrm{~min}$ before the formalin injection. Data are presented as the number of flinches or the percentage of control. Each line represents mean \pm SEM of 7 rats. Compared with control, ${ }^{\star} P<0.05,{ }^{\dagger} P<0.005,{ }^{\dagger} P<0.001$. 
termined [16], and the drugs were administered intrathecally 10 min before the delivery of intrathecal DUP-697 $(300 \mu \mathrm{g})$. The formalin test was performed 10 min later.

For the formalin test, $50 \mu \mathrm{l}$ of $5 \%$ formalin was injected subcutaneously into the plantar surface of the rat hindpaw. The number of flinches was counted for 1-min periods at 1 and $5 \mathrm{~min}$ after the formalin injection, and every 5 min thereafter. Rats were observed for a total period of $60 \mathrm{~min}$. Observed responses were divided into phase 1 (0-9 $\mathrm{min})$ and phase $2(10-60 \mathrm{~min})$ of the formalin test. The researcher who tested the drugs was blind to the drug given to each animal. Data are expressed as mean \pm SEM. Time-response data or dose-response data are shown either as the number of flinches or the percentage of control in the two phases. The control study was done with $100 \%$ DMSO, and the flinching number of the experimental group was converted to a percentage of control as follows:

$\%$ of control $=\frac{\text { Total flinching number with drug in phase } 1 \text { (2) }}{\text { Total flinching number of control in phase } 1 \text { (2) }} \times 100 \%$

Dose-response data was analyzed using the KruskalWallis test and the Mann-Whitney U test. Comparison of antagonism for the effect of DUP-697 was analyzed by Mann-Whitney U test. A $P$ value $<0.05$ was considered statistically significant.

A

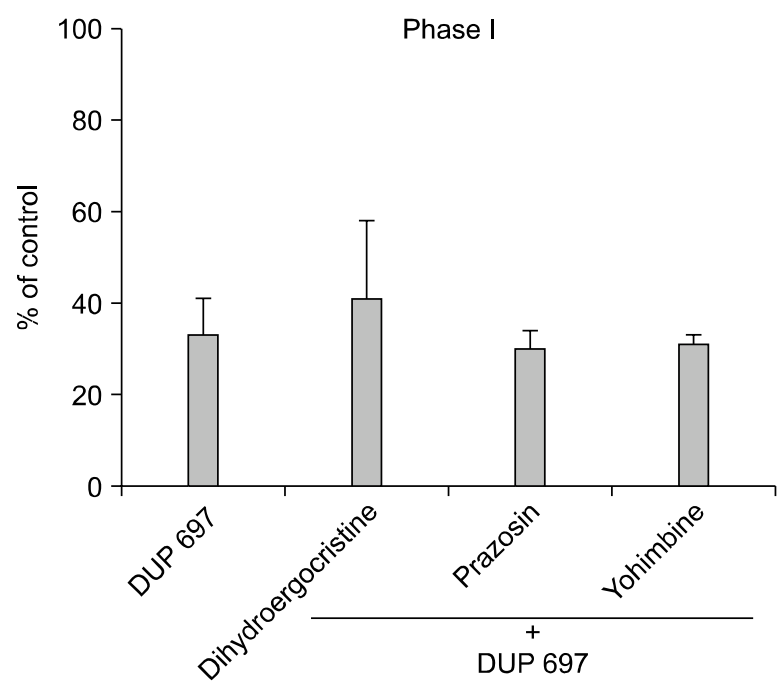

RESULTS

Subcutaneous injection of formalin into the paw produced a biphasic flinching response, with an early (phase 1) response lasting 5-10 min, and after a quiescent interval of 5-10 min, a subsequent late (phase 2) response lasting up to $60 \mathrm{~min}$. Fig. 1A shows the time course and dose-response data of intrathecal DUP-697, administered $10 \mathrm{~min}$ before formalin injection, for the formalin test. In the control group with intrathecal injection of DMSO, total flinching number was $29 \pm 3$ during phase 1 and $217 \pm 6$ during phase 2. In rats with intrathecal administration of DUP697 , total flinching number was decreased to $33-52 \%$ and $42-77 \%$ of the control group during phases 1 and 2, respectively. Fig. $\mathrm{BB}$ and $\mathrm{IC}$ show the dose-response curves of intrathecal DUP-697 on flinching response during phases 1 and 2 of the formalin test. Intrathecal DUP-697 reduced the flinching response in a dose-dependent manner during both phases of the formalin test.

The percentage of control of DUP-697 $300 \mu \mathrm{g}$ was $33 \%$ and $42 \%$ during phases 1 and 2 , respectively. When rats were pretreated intrathecally with dihydroergocristine 10 min before DUP-697 administration, the percentage of control during phases 1 and 2 was $41 \%$ and $34 \%$, respectively $(P>0.05$, Fig. 2). The percentage of control

B

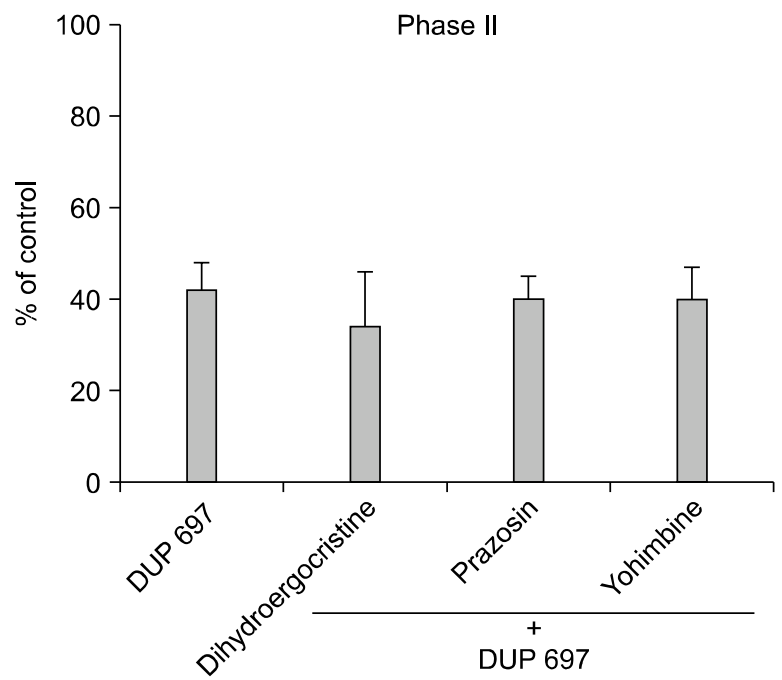

Fig. 2. The effects of intrathecal dihydroergocristine $(3 \mu \mathrm{g})$, prazosin $(3 \mu \mathrm{g})$, and yohimbine $(10 \mu \mathrm{g})$ on the antinociception of intrathecal DUP-697 (300 $\mu \mathrm{g})$ during phase $1(\mathrm{~A})$ and phase $2(\mathrm{~B})$ in the formalin test. Dihydroergocristine, prazosin, and yohimbine were administered 10 min before the delivery of DUP-697, and the formalin test was done 10 min later. None of these antagonists affected the antinociception of DUP-697 during both phases of the formalin test. Data are presented as the percentage of control. Each bar represents mean \pm SEM of 7 rats. 
of the prazosin-pretreated group during phases 1 and 2 was $30 \%$ and $40 \%$, respectively $(P>0.05$, Fig. 2 ), and that of the yohimbine-pretreated group was $32 \%$ and $40 \%$, respectively $(P>0.05$, Fig. 2). Therefore, intrathecal pretreatment with dihydroergocristine, prazosin, and yohimbine did not reverse the flinching response during both phases of the formalin test. There was no apparent abnormal behavior in the rats following the administration of the experimental drugs.

\section{DISCUSSION}

Formalin-induced nociception consists of two different nociceptive states. The first is acute nociception (phase 1), which is followed by the facilitated state (phase 2). The phase 1 response appears to result from an immediate and intense increase in the primary afferent activity. On the other hand, the phase 2 response mirrors the activation of wide dynamic range neurons of dorsal horn with a continuous low level of activity in the primary afferent. Therefore, phase 2 reflects a facilitated state which appears to be a prominent and intensified state of pain in spite of a reduced level of afferent input [17]. This pain model may serve as a tool for observing the effects of various analgesic agents on these two pain types at once.

In this study, intrathecal DUP-697 reduced the flinching response evoked by formalin injection during both phases of nociception, indicating that this selective $\mathrm{COX}-2$ inhibitor possesses a central mechanism of action at the spinal level, a finding consistent with previous reports $[2,18]$. On the other hand, pretreatment with 5-HT receptor and $\alpha 1$ and $\alpha 2$ adrenergic receptor antagonists did not antagonize the effect of intrathecally administered DUP-697. These findings suggest that the analgesic mechanisms of COX-2 inhibitor might not be associated with either the serotonergic or adrenergic systems, at least in the spinal cord.

Nevertheless, as documented earlier, previous reports support the involvement of central monoaminergic transmissions in the antinociceptive activity of COX inhibiting agents [7,8,19-22]. The discrepancy between our data and these previous reports may result from methodological differences in the experiments, such as the types of stimuli utilized, the types and doses of drugs administered, the relative affinities or selectivities of the drugs used, and the routes of drug delivery. However, several reports support our results in terms of the routes of drug delivery. Intraperitoneally administered acetylsalicylic acid and acetaminophen significantly increased 5-HT and NE content in the brain [19-21], but such an elevation was not observed in the spinal cord [21]. In addition, the antinociceptive effect of orally administered paracetamol was reversed by a $5-\mathrm{HT}_{\mathrm{IA}}$ receptor antagonist [22]. However, when the same drug was delivered intrathecally, a $5-\mathrm{HT}_{\mathrm{IA}}$ receptor antagonist did not inhibit its analgesic action [22]. An agent administered systemically can reach supraspinal sites to stimulate descending serotonergic pathways, which may participate in the antinociception produced by intraperitoneally or orally administered COX inhibiting agents. On the other hand, intrathecal delivery in the volume used in the current study $(20 \mu \mathrm{L})$ may not spread more proximally than the basal cistern and would be confined to the spinal cord $[23,24]$. Therefore, the analgesic action induced by intrathecal injection of COX-2 inhibitor in the current study might have not activated serotonergic pathways.

Systemic administration of adrenergic receptor agonists with diclofenac or ketoprofen resulted in a synergistic antinociceptive effect, while intrathecal combinations of the same drugs exhibited an additive rather than synergistic interaction [25,26]. Similarly, systemic, but not intrathecal, coadministration of metamizol, nimesulide, acetaminophen, piroxicam or naproxen with clonidine showed supraadditivity [27]. These data indicate that COX inhibiting agents may activate supraspinal mechanisms to interact with the noradrenergic system. Taken together with the results of the current investigation, these findings suggest that the antinociceptive effects of COX-2 inhibitors might involve not spinal but instead mainly supraspinal monoaminergic transmissions.

There are some limitations to the current study. First, we evaluated the roles of $5-\mathrm{HT}$ and $\alpha 1$ and $\alpha 2$ adrenergic receptor antagonists only at the spinal level. The supraspinal system may also play an important role, and the two systems may interact with each other in the nociception. Second, there are numerous subtypes of 5-HT, $\alpha 1$ and $\alpha 2$ adrenergic receptors, and the analgesic mechanism of COX-2 inhibitors might be associated with specific subtypes of those receptors. Therefore, further research will be needed to establish the properties of supraspinal pathways in relation to serotonergic and noradrenergic transmission, and the differential roles of their receptor subtypes in COX-2 inhibitor analgesia. 
In conclusion, intrathecal DUP-697, a selective COX-2 inhibitor, effectively relieved inflammatory pain in rats. The 5-HT and NE systems might not be involved in the analgesic activity of $\mathrm{COX}-2$ inhibitors on the facilitated pain state as well as on acute pain in the rat spinal cord.

\section{ACKNOWLEDGEMENTS}

This study was supported by a grant of the Korea Healthcare technology R\&D Project, Ministry for Health, Welfare \& Family Affairs, Republic of Korea (A100619).

\section{REFERCENCES}

1. Beiche F, Scheuerer S, Brune K, Geisslinger G, GoppeltStruebe M. Up-regulation of cyclooxygenase-2 mRNA in the rat spinal cord following peripheral inflammation. FEBS Lett 1996; 390: 165-9.

2. Choi CH, Kim WM, Lee HG, Jeong CW, Kim CM, Lee SH, et al. Roles of opioid receptor subtype in the spinal antinociception of selective cyclooxygenase 2 inhibitor. Korean J Pain 2010; 23: 236-41.

3. Hamza M, Dionne RA. Mechanisms of non-opioid analgesics beyond cyclooxygenase enzyme inhibition. Curr Mol Pharmacol 2009; 2: 1-14.

4. Marlier L, Teilhac JR, Cerruti C, Privat A. Autoradiographic mapping of $5-H T 1,5-H T 1 A, 5-H T 1 B$ and $5-H T 2$ receptors in the rat spinal cord. Brain Res 1991; 550: 15-23.

5. Hösli E, Hösli L. Evidence for the existence of alpha- and beta-adrenoceptors on neurones and glial cells of cultured rat central nervous system--an autoradiographic study. Neuroscience 1982; 7: 2873-81.

6. Fürst S. Transmitters involved in antinociception in the spinal cord. Brain Res Bull 1999; 48: 129-41.

7. Sandrini M, Vitale G, Pini LA. Effect of rofecoxib on nociception and the serotonin system in the rat brain. Inflamm Res 2002; 51: 154-9.

8. Taiwo YO, Levine JD. Prostaglandins inhibit endogenous pain control mechanisms by blocking transmission at spinal noradrenergic synapses. J Neurosci 1988; 8: 1346-9.

9. Yaksh TL, Rudy TA. Chronic catheterization of the spinal subarachnoid space. Physiol Behav 1976; 17: 1031-6.

10. Choi Jl, Yoo KY, Yoon MH. Effect of serotonergic receptors on the antinociception of intrathecal gabapentin in the formalin test of rats. J Korean Pain Soc 2002; 15: 19-25.

11. Coppi $G$. Dihydroergocristine. A review of pharmacology and toxicology. Arzneimittelforschung 1992; 42: 1381-90.

12. Grognet JM, Rivière R, Istin M, Zanotti A, Coppi G. The pharmacokinetics of dihydroergocristine after intravenous and oral administration in rats. Arzneimittelforschung 1992; 42 :
1394-6.

13. Doxey JC, Roach AG, Smith CF. Studies on RX 781094: a selective, potent and specific antagonist of alpha 2-adrenoceptors. Br J Pharmacol 1983; 78: 489-505.

14. Hamilton CA, Reid JL, Vincent J. Pharmacokinetic and pharmacodynamic studies with two alpha-adrenoceptor antagonists, doxazosin and prazosin in the rabbit. $\mathrm{Br} J$ Pharmacol 1985; 86: 79-87.

15. Hubbard JW, Pfister SL, Biediger AM, Herzig TC, Keeton TK. The pharmacokinetic properties of yohimbine in the conscious rat. Naunyn Schmiedebergs Arch Pharmacol 1988; 337: $583-7$.

16. Yoon MH, Choi Jl, Jeong SW. Spinal gabapentin and antinociception: mechanisms of action. J Korean Med Sci 2003; 18: 255-61.

17. Puig S, Sorkin LS. Formalin-evoked activity in identified primary afferent fibers: systemic lidocaine suppresses phase-2 activity. Pain 1996; 64: 345-55.

18. Nishiyama T. Analgesic effects of intrathecally administered celecoxib, a cyclooxygenase-2 inhibitor, in the tail flick test and the formalin test in rats. Acta Anaesthesiol Scand 2006; 50: 228-33.

19. Pini LA, Vitale G, Sandrini M. Serotonin and opiate involvement in the antinociceptive effect of acetylsalicylic acid. Pharmacology 1997; 54: 84-91.

20. Vitale G, Pini LA, Ottani A, Sandrini M. Effect of acetylsalicylic acid on formalin test and on serotonin system in the rat brain. Gen Pharmacol 1998; 31: 753-8.

21. Courade JP, Caussade F, Martin K, Besse D, Delchambre C, Hanoun $\mathrm{N}$, et al. Effects of acetaminophen on monoaminergic systems in the rat central nervous system. Naunyn Schmiedebergs Arch Pharmacol 2001; 364: 534-7.

22. Bonnefont J, Alloui A, Chapuy E, Clottes E, Eschalier A. Orally administered paracetamol does not act locally in the rat formalin test: evidence for a supraspinal, serotonin-dependent antinociceptive mechanism. Anesthesiology 2003; 99: 97681.

23. Fairbanks CA. Spinal delivery of analgesics in experimental models of pain and analgesia. Adv Drug Deliv Rev 2003; 55: $1007-41$.

24. Xu JJ, Walla BC, Diaz MF, Fuller GN, Gutstein HB. Intermittent lumbar puncture in rats: a novel method for the experimental study of opioid tolerance. Anesth Analg 2006; 103: 714-20.

25. Pinardi G. Sierralta F. Miranda HF. Interaction between the antinociceptive effect of ketoprofen and adrenergic modulatory systems. Inflammation 2001; 25: 233-9.

26. Miranda HF, Sierralta F. Pinardi G. An isobolographic analysis of the adrenergic modulation of diclofenac antinociception. Anesth Analg 2001; 93: 430-5.

27. Miranda HF, Pinardi G. Isobolographic analysis of the antinociceptive interactions of clonidine with nonsteroidal anti-inflammatory drugs. Pharmacol Res 2004; 50: 273-8. 